\title{
Personal Accounts of Young-Onset Colorectal Cancer Organized as Patient-Reported Data: Protocol for a Mixed Methods Study
}

Klay Lamprell ${ }^{{ }^{*}}, \mathrm{PhD}$; Diana Fajardo Pulido ${ }^{1^{*}}, \mathrm{MPH}, \mathrm{MHM}$; Yvonne Tran ${ }^{1^{*}}, \mathrm{PhD}$; Bróna Nic Giolla Easpaig ${ }^{{ }^{*}}, \mathrm{PhD}$ Winston Liauw $^{2 *}$, MBBS, MMed; Gaston Arnolda ${ }^{1^{*}}, \mathrm{PhD}$; Jeffrey Braithwaite ${ }^{1^{*}}, \mathrm{PhD}$

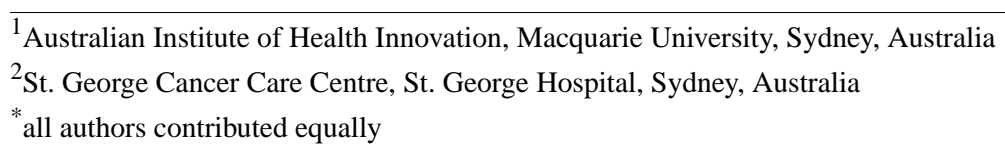

Corresponding Author:

Klay Lamprell, $\mathrm{PhD}$

Australian Institute of Health Innovation

Macquarie University

Level 6, 75 Talavera Road

New South Wales

Sydney, 2109

Australia

Phone: 61298502472

Email: klay.lamprell@mq.edu.au

\section{Abstract}

Background: Young-onset colorectal cancer is a contemporary issue in need of substantial research input. The incidence of colorectal cancer in adults younger than 50 years is rising in contrast to the decreasing incidence of this cancer in older adults. People with young-onset colorectal cancer may be at that stage of life in which they are establishing their careers, building relationships with long-term partners, raising children, and assembling a financial base for the future. A qualitative study designed to facilitate triangulation with extant quantitative patient-reported data would contribute the first comprehensive resource for understanding how this distinct patient population experiences health services and the outcomes of care throughout the patient pathway.

Objective: The aim of this study was to undertake a mixed-methods study of qualitative patient-reported data on young-onset colorectal cancer experiences and outcomes.

Methods: This is a study of web-based unsolicited patient stories recounting experiences of health services and clinical outcomes related to young-onset colorectal cancer. Personal Recollections Organized as Data (PROD) is a novel methodology for understanding patients' health experiences in order to improve care. PROD pivots qualitative data collection and analysis around the validated domains and dimensions measured in patient-reported outcome and patient-reported experience questionnaires. PROD involves 4 processes: (1) classifying attributes of the contributing patients, their disease states, their routes to diagnosis, and the clinical features of their treatment and posttreatment; (2) coding texts into the patient-reported experience and patient-reported outcome domains and dimensions, defined a priori, according to phases of the patient pathway; (3) thematic analysis of content within and across each domain; and (4) quantitative text analysis of the narrative content.

Results: Relevant patient stories have been identified, and permission has been obtained for use of the texts in primary research. The approval for this study was granted by the Macquarie University Human Research Ethics Committee in June 2020. The analytical framework was established in September 2020, and data collection commenced in October 2020. We will complete the analysis in March 2021 and we aim to publish the results in mid-2021.

Conclusions: The findings of this study will identify areas for improvement in the PROD methodology and inform the development of a large-scale study of young-onset colorectal cancer patient narratives. We believe that this will be the first qualitative study to identify and describe the patient pathway from symptom self-identification to help-seeking through to diagnosis, treatment, and to survivorship or palliation for people with young-onset colorectal cancer.

International Registered Report Identifier (IRRID)： DERR1-10.2196/25056

(JMIR Res Protoc 2021;10(2):e25056) doi: $\underline{10.2196 / 25056}$ 


\section{KEYWORDS}

colorectal cancer; PROMs; young-onset cancer; cancer; patient reported outcome

\section{Introduction}

Routine systematic collection of patient-reported outcome (PRO) and patient-reported experience (PRE) data is of considerable interest to health systems worldwide and is the subject of ongoing investment [1,2]. Validated instruments-most often in the form of standardized questionnaires - are regularly used to measure patients' perspectives on the quality of health services and personal outcomes of clinical management care. These data are considered foundational in understanding the effects of health care on patients' daily lives [3] and for making improvements in health care delivery [4,5]. Mixed-methods approaches [6] are increasingly becoming common in the collection of PRO and PRE data. Measurement instruments are sometimes supplemented with open-ended, free-text questions [7] to capture nuanced and idiosyncratic perspectives [5,8-10]. This descriptive material $[7,11]$ has been shown to contextualize responses to closed questions [12] to provide more detail about the relational aspects of patients' experiences [11] and to be more specific about the aspects of care that can be improved to promote better outcomes [11-13].

Qualitative researchers investigating patients' experiences of care and perspectives on outcomes may have opportunities to facilitate mixed-methods approaches [6] for the collection of patient-reported data. In this paper, we present a methodology for producing qualitative data that effectively triangulates $[6,14,15]$ with quantitative colorectal PRO and PRE data [16-19]. The methodology, which we call as Personal Recollections Organized as Data (PROD), pivots data collection and analysis around the validated domains and dimensions measured by PRO and PRE instruments [20-23]. The aim is to facilitate synthesis of patient-reported evidence across research projects. To our knowledge, this is a novel approach to qualitative patient experience data collection.

PROD draws on the "framework method" [24,25], in which free text or narrative data are organized into classifications that have been determined a priori and utilizes thematic/inductive techniques to facilitate the interpretation of emergent PRE and PRO topics [16-19], including quantitative text mining techniques, which are a resource-efficient means of identifying patterns and modelling relationships between topics [12,24,25].

The PROD method will be used to investigate the perspectives of people with young-onset colorectal cancer. The increasing incidence of colorectal cancer in people younger than 50 years has been described as an alarming phenomenon [26] within the wider population of patients with colorectal cancer [27-32]. The incidence of young-onset colorectal cancer has risen by up to $2 \%$ per year worldwide while that of colorectal cancer in older adults is declining by up to $3 \%$ per year [26,31,33,34]. Dietary and lifestyle changes framed by shifts in global food chains have been proposed as causes for the rise in young-onset colorectal cancer [35]. Additionally, colorectal cancer awareness campaigns and screening programs are directed at people aged 50 years and older [35]. Patients with colorectal cancer who are younger than 50 years are twice as likely as older patients to experience missed diagnostic opportunities by physicians [36], significantly more likely to be diagnosed at an advanced stage of the disease [30,32], have a greater likelihood of aggressive therapeutic management [32], and will commonly have poorer quality of life outcomes [13,37-39].

We have knowledge of this patient population from age-stratified data of the wider colorectal cancer population; however, there has been limited attention on patients with young-onset colorectal cancer as a specific patient community. Patients younger than 50 years are at that stage of life in which they are establishing careers, building relationships with long-term partners, raising children, and assembling a financial base for the future. Their perspectives on their experiences of health services and outcomes of care may be different from those of older patients with colorectal cancer.

Our study aims to address the gap in qualitative patient-reported data on young-onset colorectal cancer by investigating the personal accounts published online by these patients. Web-based autobiographical accounts of health care experiences and outcomes are emerging sources of qualitative patient-reported data on disease-specific and condition-specific patient experience [40-42]. The accounts we will access are extant texts $[20,43]$ in contrast to interactive forms of web-based self-narration in blogs and social media, which have been investigated elsewhere $[44,45]$. These unsolicited narratives, not produced in response to a research inquiry [20], provide rich detail on the health care experiences and issues that matter to these patients [42].

Patient narratives commonly describe the entire health care journey-from initial help-seeking to current survivor or palliative care status [40] - from the patients' points of view [40]. They feature highly personal perspectives on the performance of health services and physical, emotional, and social outcomes of medical management across the trajectory of care [42]. As sources of patient-reported data, these narratives offer a counterpoint to data produced from cross-sectional surveys. They provide significantly more descriptive data than those that can be derived from supplementary free-text questions in PRE and PRO questionnaires. Given that qualitative research by participant interview can be a labor-intensive and time-intensive process, there is an advantage also in the accessibility of patients' unsolicited narratives with respect to ethical considerations [46]. The PROD methodology, with its clear thematization of coding around existing PRE/PRO dimensions, offers access to rich, longitudinally framed, patient-reported data.

\section{Methods}

\section{Design Methodology}

A flowchart of the study design is depicted in Figure 1. This is a study of personal patient stories published on websites hosted by 3 established colorectal disease support organizations: Bowel 
Cancer Australia, Bowel Cancer UK, and Bowel Cancer NZ. These countries were chosen as they are all English-speaking and have universal health care access. This project will access the public domain sections of these websites in which people post accounts of their experiences under banners such as "real life stories" or "your stories."

Figure 1. Flowchart of the study design. CRC: colorectal cancer; Y-CRC: young-onset colorectal cancer; PRE: patient-reported experience; PRO: patient-reported outcome; PROD: personal recollections organized as data.

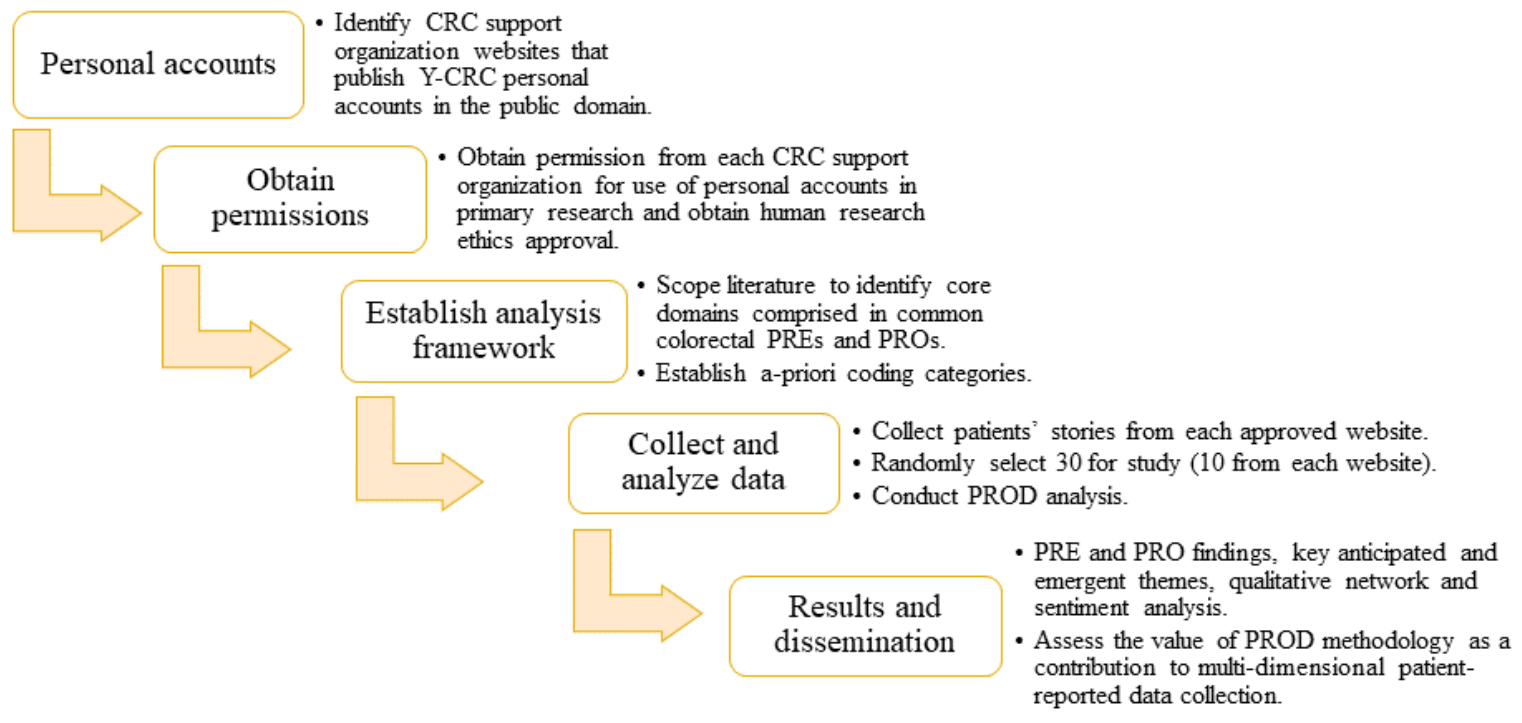

\section{Ethical Considerations}

There is no established ethical stance relating specifically to research involving unsolicited web-based narratives. We have obtained permission from each of the organizations to analyze these personal accounts and to use deidentified excerpts and quotes in reports of findings from the study. The organizations that host the websites have agreements with individual patient contributors regarding the use of their information and narrative material. These contributors are not direct participants of our study. However, the study of unsolicited autobiographical narratives is a unique research space with particular ethical issues relating to recruitment [47]. To establish the ethical position of this study, we refer to the Australian National Statement on Ethical Conduct in Human Research (2007-Updated 2018) [48], which indicates that privacy concerns arise when the proposed access to, or use of, the data or information does not match the expectations of the individuals from whom this data or information was obtained or to whom it relates. Therefore, we were granted ethical and scientific approval for this project from the Macquarie University Human Research Ethics Committee (MQ HREC Reference No:52020666115757). In publishing their personal accounts on the selected colorectal support organization websites, these contributors agreed that their stories would be made available for public access and used to raise awareness of young-onset colorectal cancer. This study meets the expectations of the contributors. Moreover, this study does not place burdens of active research participation on these potentially vulnerable contributors [49,50]. Additionally, unsolicited accounts enact the values of patient-reported data.

\section{Recruitment}

We defined inclusion and exclusion criteria to identify the types of personal accounts published on these sites that would be relevant to the study's aims. We will include personal accounts that are written by people diagnosed with colorectal cancer (self-reported disease state, including but not limited to cancer of the colon, cancer of the rectosigmoid junction, and cancer of the rectum) [13]; before their 50th birthday; published in the public domain spaces of websites hosted by the 3 prominent colorectal disease support organizations, under agreement for the public dissemination and republication of the material; written by people aged 18 years or older at the time of submitting their personal accounts for publication on the website; and autobiographical, first-person accounts of experiences and outcomes relating to care for colorectal cancer. We will exclude personal accounts from the study if they solely comprise feedback on, or criticism of, a named institution or clinician or substantially describe someone else's experiences and outcomes relating to care for young-onset colorectal cancer. We are not including serialized narrative material published as ongoing weblogs or blogs. We will take a random sample of 30 personal accounts from the eligible selection of personal stories using the Microsoft Excel (2011) random function, comprising 10 samples from the patient stories published on each of the 3 websites.

\section{Data Extraction and Analysis}

Narrative accounts will be downloaded from websites and collected and analyzed using the qualitative analysis software NVivo 12 Plus (QSR International) [51]. To avoid identification of individuals, each story will be deidentified and assigned a unique identifier code. Our framework method for qualitative analysis [24] identifies a priori what features to account for in our research reporting [16]. We detail our process for establishing the analytical framework in the following section on PRE and PRO domain coding. The PROD approach involves 4 key steps in creating a new structure for the data, as shown in Figure 2: (1) classifying attributes of the contributors, their 
disease states, their routes to diagnosis, and the clinical features of their treatment and posttreatment; (2) coding each line of each narrative into PRE and PRO categories and domains according to phases of the patient pathway; (3) thematic analysis of content within each domain; and (4) quantitative analysis of the narrative content.

Figure 2. Overview of the framework for analysis. PRE: patient-reported experience; PRO: patient-reported outcome.

\begin{tabular}{|c|c|c|c|}
\hline $\begin{array}{l}\text { Multiple choice and } \\
\text { yes/no questions: } \\
\text { patient contributor } \\
\text { demographics and } \\
\text { disease state, } \\
\text { key characteristics of } \\
\text { route to diagnosis, } \\
\text { clinical characteristics } \\
\text { of treatment and } \\
\text { posttreatment } \\
\text { therapies. }\end{array}$ & $\begin{array}{l}\text { Multiple read- } \\
\text { throughs of whole } \\
\text { text. Line-by-line } \\
\text { coding of text into } \\
\text { domains of PRE/PRO } \\
\text { categories and } \\
\text { identify outlier text. } \\
\text { Iterative team cross- } \\
\text { checking and } \\
\text { discussion to reach } \\
\text { agreement. }\end{array}$ & $\begin{array}{l}\text { Examine text within } \\
\text { PRE/PRO domains } \\
\text { and outlier text to } \\
\text { identify anticipated } \\
\text { and emergent themes. } \\
\text { Explore patterns and } \\
\text { singular perspectives. } \\
\text { Iterative team cross- } \\
\text { checking and } \\
\text { discussion to reach } \\
\text { agreement. }\end{array}$ & $\begin{array}{l}\text { Interpret PRE/PRO } \\
\text { themes within each } \\
\text { text using network } \\
\text { analysis and } \\
\text { quantitative text } \\
\text { analysis methods. } \\
\text { Team to compare and } \\
\text { contrast qualitative } \\
\text { thematic and } \\
\text { quantitative findings. }\end{array}$ \\
\hline $\begin{array}{l}\text { Attribute } \\
\text { coding }\end{array}$ & $\begin{array}{l}\text { Coding for } \\
\text { PRE / PRO }\end{array}$ & $\begin{array}{l}\text { Thematic } \\
\text { analysis }\end{array}$ & $\begin{array}{c}\text { Quantitative } \\
\text { analysis }\end{array}$ \\
\hline \multicolumn{4}{|c|}{ Text coded along patient pathway (diagnosis, treatment, survivorship/palliative) } \\
\hline
\end{tabular}

Manual coding and analysis will be undertaken by the process of line-by-line attention to the content in a series of iterative readings. Consistent with the principles of qualitative research, each step of the data extraction and analytical process will be undertaken by at least two researchers [18], as qualitative work with narrative data is interpretive, even when coding to a framework of categories and domains established a priori.

With research questions to guide their choices, 2 researchers working together and constantly comparing their findings can arrive at agreement on the significance of the narrative content and the conclusions that can be drawn from it [18]. The third researcher will validate the findings of the thematic analysis, the fourth researcher will undertake the quantitative analysis, and the team will collaborate to reach consensus on the significance of the findings in relation to triangulation with extant colorectal PRE and PRO data.

\section{Attribute Coding}

The first step of the PROD analysis is to identify and classify the key demographic characteristics of the patient contributors, their disease states, the features of their diagnostic pathways, and the clinical features of their treatment and posttreatment phases. We will organize these data in a framework of yes/no and multiple choice categories. The sets of selections are based on conventional research participant attributes and adapted to the level of detail obtainable from unsolicited narratives. In these accounts, attributes such as age, gender, relationship status, and current disease status information may be unknown from the basic information provided in a source website. These characteristics may only be identifiable with close attention to both content and language in a narrative [52], and even then, may only be inferred from implicit clues [40].

\section{PRE and PRO Domain Coding}

To develop a set of domains and subdomain items for the a priori analytical framework, we reviewed literature on core outcome sets for PRE and PRO measures [2,23,53] and mixed-methods approaches for analyzing PRE and PRO data [12,54-57]. Our conceptual approach to PRE and PRO domain coding is presented in Figure 3. The domains and subdomain items comprised in our analytical framework are presented in Table 1 and also described below. 
Figure 3. Mixed-methods approach for capturing different dimensions in patient-reported data.

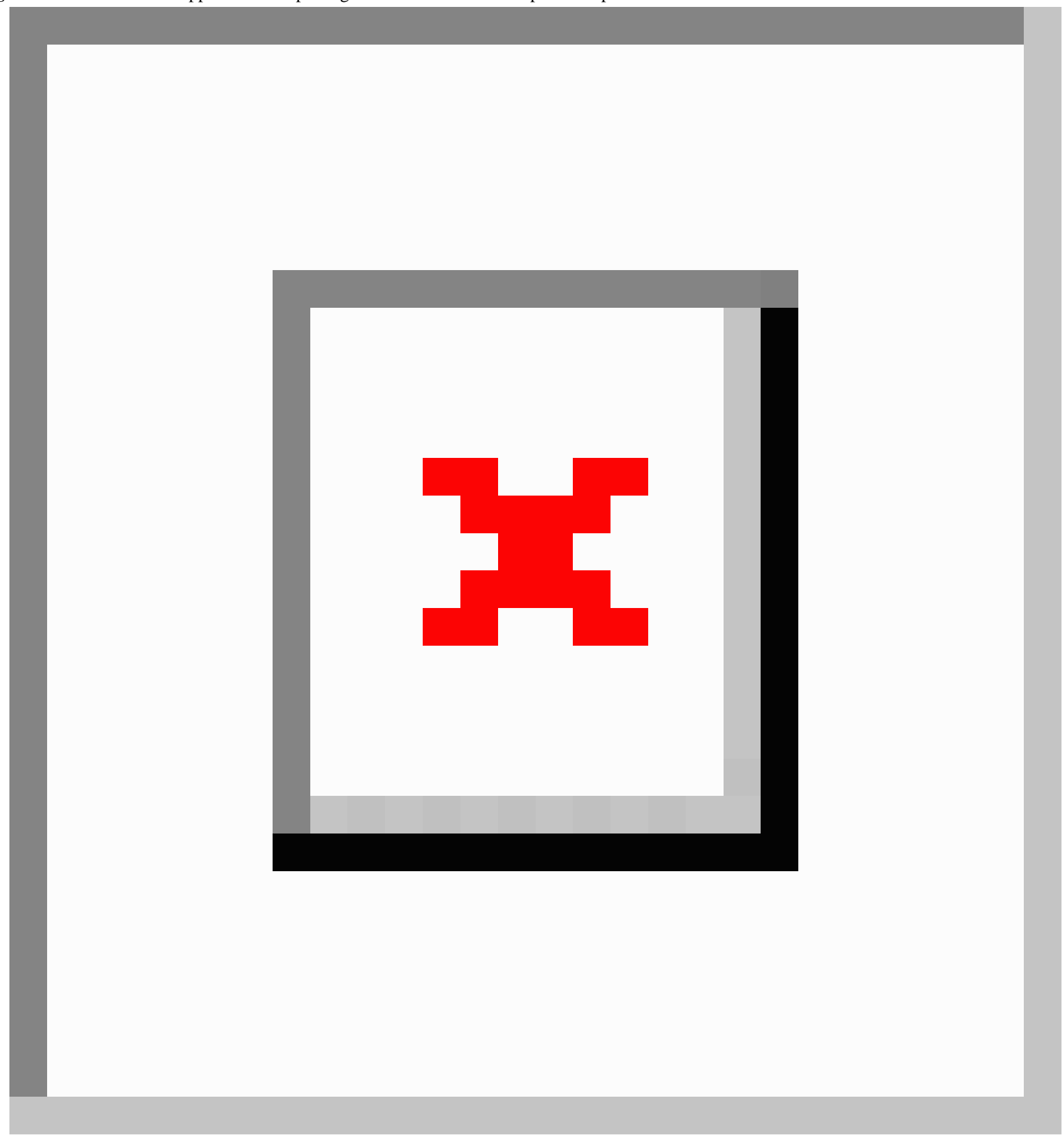


Table 1. Analysis of personal recollections organized as data using the a priori coding framework.

\begin{tabular}{|c|c|}
\hline Domains, subdomains & Measures \\
\hline \multicolumn{2}{|l|}{ Attribute coding } \\
\hline Population characteristics & Gender, marital status, children, date of publication \\
\hline Disease characteristics and management & $\begin{array}{l}\text { Age at diagnosis, current status of disease/diagnosis, stage and type of bowel cancer at diagnosis, } \\
\text { type of initial medical consultation for symptoms, family history of } \mathrm{CRC}^{\mathrm{a}} \text {, investigation for CRC, } \\
\text { time from first consultation for illness symptoms to first diagnosis of CRC, discussion of } \\
\text { immunotherapy/precision treatment, clinical trials, biomarker-based approach }\end{array}$ \\
\hline Route to diagnosis & $\begin{array}{l}\text { Symptoms prior to first diagnosis, diagnosis received prior to CRC diagnosis, treatments given } \\
\text { for diagnosis prior to CRC, investigations undertaken to diagnose CRC, other conditions and } \\
\text { genetic syndromes discussed }\end{array}$ \\
\hline Treatment and posttreatment & Treatment received, posttreatment effects \\
\hline \multicolumn{2}{|l|}{ Domain coding } \\
\hline \multicolumn{2}{|l|}{ Patient-reported experience } \\
\hline Functional & $\begin{array}{l}\text { Financial impact or costs associated with care } \\
\text { Physical context (access, cleanliness, and comfort) } \\
\text { Process (continuity and co-ordination of care, scheduling, and waiting times) } \\
\text { Quality and efficiency of clinical care }\end{array}$ \\
\hline Relational & $\begin{array}{l}\text { Collaborative nature of interactions (provider and admin) } \\
\text { Informational or educational nature of interactions (clinical and practical information, scheduling } \\
\text { and waiting times) } \\
\text { Interpersonal nature of the interactions (provider and admin) }\end{array}$ \\
\hline \multicolumn{2}{|l|}{ Patient-reported outcome } \\
\hline $\begin{array}{l}\text { Everyday living or usual } \\
\text { activities }\end{array}$ & $\begin{array}{l}\text { Caring for family or dependents } \\
\text { Domestic chores } \\
\text { Gastrointestinal function } \\
\text { Getting around or mobility } \\
\text { Holidays } \\
\text { Independence } \\
\text { Living conditions and environment } \\
\text { Personal or self-care } \\
\text { Recreation }\end{array}$ \\
\hline Money matters & $\begin{array}{l}\text { Finances or financial services } \\
\text { Planning the future } \\
\text { Work }\end{array}$ \\
\hline Self and others & $\begin{array}{l}\text { Anxiety or depression } \\
\text { Body image } \\
\text { Existential matters } \\
\text { Isolation } \\
\text { Pain or discomfort } \\
\text { Sexual matters } \\
\text { Starting a new family } \\
\text { Support and communication }\end{array}$ \\
\hline Additional issues & Others \\
\hline
\end{tabular}

${ }^{\mathrm{a} C R C}$ : colorectal cancer.

\section{PRO Domains}

We reviewed general cancer and colorectal-specific PRO instruments $[2,23,53,58,59]$, including the European Quality of Life Questionnaire-5 dimension (EQ-5D) [60], which assesses health outcomes of care across 5 quality of life domains-anxiety/depression, mobility, pain/discomfort, self-care, and usual activities [60]; the European Organization for Research and Treatment of Cancer-Quality of Life Questionnaire-29-item colon and rectum cancer-site specific (EORTC-QLQ-CR29), the Medical Outcomes Study 12-Item 
Health Survey, the Functional Assessment of Cancer Therapy-Colorectal (FACT-C), Edmonton Symptom Assessment System, and the Social Difficulties Inventory instrument-21 item (SDI-21), which assesses the impact of cancer on family life, social activities, personal matters, finances, and work. Of these, we selected the SDI-21 and the EQ-5D as being the most relevant to our research interests and for the collection of data from unsolicited free text narratives. We selected these instruments based on the volume of applications in the context of colorectal cancer $[12,13,58,61]$, the applicability of these instruments in people with colorectal cancer across all disease stages and phases of treatment $[59,61]$, and because the domains and items comprised in these instruments offer a balance of broad functional and psychosocial outcomes [13,61-63].

We used 3 core outcome sets from the SDI-21 as the thematic domains for PRO coding: "Everyday Living," "Money Matters," and "Self and Others." We also added a category for "Additional issues" to capture events and perspectives not comprised in these thematic domains. Where possible, we consolidated individual scaled items from SDI-21 outcome sets. For example, in the domain "Money Matters," we absorbed the items "Welfare benefits," "Finances," and "Finance services" into a single item called "Finances or financial services." Similarly, we synthesized 3 communication and support items into 1 item called "Support and communication." We also incorporated the SDI-21 single item set into 3 core thematic domains, bringing "Sexual Matters" and "Plans to have a family" into the "Self and others" domain and "Holidays" and "Where you live" into the "Everyday living" domain (Table 1).

While the EQ-5D questionnaire and SDI-21 feature common outcomes, the EQ-5D instrument also accounts for issues relating to pain and discomfort and the psychosocial aspects of everyday life, such as anxiety and depression. We included these items in the framework domain called "Self and others." To code for issues that are particular to people with colorectal cancer and to cover all items included in colorectal cancer-specific PRO questionnaires such as EORTC-QLQ-CR29 and FACT-C [53], we introduced the item, "Gastrointestinal function" into the "Everyday living" domain.

\section{PRE Domains}

PRE-questionnaires are commonly designed to examine patients' experiences of particular health organizations, such as the National Health Service National Cancer Patient Experience Survey, or the services offered in certain health settings [64]. The EORTC, for example, publishes PRE-questionnaires specific to inpatients and inpatient experiences, communication with professionals, and information provision. Given that our data set was drawn from websites in 3 countries and that contributors chose the aspects of their experiences that they wished to describe, we required a broad-ranging generic set of PRE domains and subdomain items for our analytical framework [64].

Rather than selecting domains from a particular PRE instrument, we reviewed the literature to identify the core concepts underpinning PRE-questionnaires. We identified that patient experience outcomes are measured broadly for either relational or functional aspects of experience [64-66]. We used these as the 2 PRE domains in our analytical framework. Relational outcomes account for the interpersonal nature of patient-provider communications, patient-provider collaboration, and information provision to patients $[65,67]$. Functional outcomes account for the organizational and practical aspects of care, environments of care delivery, and the financial impact of care $[65,67]$ (Table 1).

\section{Patient Pathway Coding}

From patients' perspectives, experiences of health services and outcomes of care occur as a continuum of patient journey within and across the phases of the patient pathway [40]. We will undertake a patient pathway analysis of the PRE and PRO data by coding for 3 key phases of the patient pathway: diagnosis, treatment, and survivorship/palliative care (Figure 2) [36,68,69].

\section{Thematic Analysis}

There are 4 steps in our thematic analysis: coding for concepts, categorizing codes into groups, detecting patterns across categories, and interpreting themes within and across these patterns [70]. This process transforms the text into a narrative dataset, moving from highly descriptive findings to highly interpretative findings [16,20].

\section{Quantitative Analysis}

We will investigate opportunities to interpret the data quantitatively by means of network analysis [71] and quantitative text-based analysis, which uses automated natural language processing to analyze topics across different documents [12] and can measure sentiments within texts. This method may draw out aspects that contextualize other findings [12,13]. Quantitative approaches to analyzing unstructured text are emerging; however, as yet, there is little consensus on optimal strategies $[12,46]$.

\section{Methodological Limitations}

Our methods will have limitations, including that we will be dealing with text not written for research purposes, not all text will map to our framework, and the data are subjective and will require interpretation. Additionally, data reported in different health systems will need to be seen in the light of those structural and contextual differences. Further, regardless of validity, there are limitations to standardized instruments and these limitations will be reflected in the a priori domains and dimensions that are the foundation of our analytical framework.

\section{Results}

After searching the 3 colorectal cancer patient support and advocacy websites selected for this study, we found that each featured story meets all the inclusion criteria. All texts were downloaded from the internet into the NVivo analysis software, and analysis commenced in September 2020 on the 30 texts randomly selected for this study. We will complete the analysis in March 2021 and we aim to publish the results in mid-2021.

\section{Discussion}

The PROD method for systematically extracting relevant patient-reported data from free-text patient stories aims to 
maximize the benefits of rich detailed patient-perspective data that can be drawn from patient narratives while framing findings to facilitate data triangulation with patient-reported results from PROs and PREs. Young-onset colorectal cancer is a contemporary issue in need of substantial research input [32,69]. We believe that this will be the first qualitative study to identify and describe the patient pathway from self-symptom identification to help-seeking through diagnosis, treatment, and into survivorship or palliation for people with young-onset colorectal cancer. Unsolicited autobiographical narratives offer a unique opportunity to collect patient-reported data that expose this real-world perspective [40], which is particularly valuable in this age of SARS-COV-2.
The findings from this study have the potential to provide information in a form that can modify habitual thinking and influence clinicians' cognitive biases [72,73] about age-related criteria for colorectal cancer risk assessment and diagnostic practice. Knowledge of the diagnostic and therapeutic experiences of patients with young-onset colorectal cancer may facilitate greater awareness of colorectal cancer symptoms in people younger than 50 years [74], promote patient proactivity in seeking help, and highlight the importance of identifying hereditary conditions that predispose young people to colorectal cancer $[28,75,76]$. There is significant potential for the patient-reported data from this study to make a real-world difference to people with young-onset colorectal cancer.

\section{Acknowledgments}

This work was supported by a National Health and Medical Research Council Centre for Research Excellence Grant in Implementation Science in Oncology (APP1135048). The authors thank the colorectal patient support organizations, namely, Bowel Cancer Australia, Bowel Cancer New Zealand, and Bowel Cancer UK for supporting this research. We are grateful to the people whose stories are published on these websites for generously sharing their memories, thoughts, and feelings about their experiences of colorectal cancer and the events of their medical care.

\section{Authors' Contributions}

KL devised the study. KL, DFP, and YT undertook the detailed design of the study, in consultation with all authors. KL and DFP prepared the study materials. KL wrote the first draft of the manuscript. All authors contributed to and approved the final manuscript.

\section{Conflicts of Interest}

None declared.

\section{References}

1. Bottomley A, Pe M, Sloan J, Basch E, Bonnetain F, Calvert M, et al. Analysing data from patient-reported outcome and quality of life endpoints for cancer clinical trials: a start in setting international standards. The Lancet Oncology 2016 Nov;17(11):e510-e514 [FREE Full text] [doi: 10.1016/s1470-2045(16)30510-1]

2. Greenhalgh J, Dalkin S, Gooding K. Functionality and feedback: a realist synthesis of the collation, interpretation and utilisation of patient-reported outcome measures data to improve patient care. Health Serv Delivery Res 2017;5(2):1-280. [doi: 10.3310/hsdr05020] [Medline: 28121094]

3. Nelson EC, Eftimovska E, Lind C, Hager A, Wasson JH, Lindblad S. Patient reported outcome measures in practice. BMJ 2015 Feb 10;350:g7818. [doi: 10.1136/bmj.g7818] [Medline: 25670183]

4. Bull C, Byrnes J, Hettiarachchi R, Downes M. A systematic review of the validity and reliability of patient-reported experience measures. Health Serv Res 2019 Oct;54(5):1023-1035 [FREE Full text] [doi: 10.1111/1475-6773.13187] [Medline: 31218671$]$

5. de Silva D. Measuring patient experience. The Health Foundation. 2013. URL: https://www.health.org.uk/publications/ measuring-patient-experience [accessed 2020-10-15]

6. Carter N, Bryant-Lukosius D, DiCenso A, Blythe J, Neville AJ. The use of triangulation in qualitative research. Oncol Nurs Forum 2014 Sep;41(5):545-547. [doi: 10.1188/14.ONF.545-547] [Medline: 25158659]

7. Rogers S, Barber B. Using PROMs to guide patients and practitioners through the head and neck cancer journey. PROM 2017 Nov; Volume 8:133-142. [doi: 10.2147/prom.s129012]

8. Corner J, Wagland R, Glaser A, Richards SM. Qualitative analysis of patients' feedback from a PROMs survey of cancer patients in England. BMJ Open 2013;3(4) [FREE Full text] [doi: 10.1136/bmjopen-2012-002316] [Medline: 23578681]

9. Cheng KKF, Clark AM. Qualitative Methods and Patient-Reported Outcomes. International Journal of Qualitative Methods 2017 Mar 27;16(1). [doi: 10.1177/1609406917702983]

10. Huppertz J, Smith R. The value of patients' handwritten comments on HCAHPS surveys. J Healthc Management. 2014. URL: https://journals.lww.com/jhmonline/Fulltext/2014/01000/The Value of Patients Handwritten Comments on.7. aspx [accessed 2020-01-01]

11. Tsianakas V, Maben J, Wiseman T, Robert G, Richardson A, Madden P, et al. Using patients' experiences to identify priorities for quality improvement in breast cancer care: patient narratives, surveys or both? BMC Health Serv Res 2012 Aug 22;12:271 [FREE Full text] [doi: 10.1186/1472-6963-12-271] [Medline: 22913525] 
12. Wagland R, Recio-Saucedo A, Simon M, Bracher M, Hunt K, Foster C, et al. Development and testing of a text-mining approach to analyse patients' comments on their experiences of colorectal cancer care. BMJ Qual Saf 2016 Aug;25(8):604-614. [doi: 10.1136/bmjqs-2015-004063] [Medline: 26512131]

13. Wood C, Lawton S, Downing A. Quality of life of colorectal cancer survivors in England: report on a national survey of colorectal cancer survivors using Patient Reported Outcome Measures (PROMs). UK: NHS England. 2015. URL: https:/ /www.england.nhs.uk/wp-content/uploads/2015/03/colorectal-cancer-proms-report-140314.pdf [accessed 2020-06-10]

14. Reed JE, Howe C, Doyle C, Bell D. Simple rules for evidence translation in complex systems: A qualitative study. BMC Med 2018 Jun 20;16(1):92 [FREE Full text] [doi: 10.1186/s12916-018-1076-9] [Medline: 29921274]

15. Wilson R. Patient led PROMs must take centre stage in cancer research. Res Involv Engagem 2018 Feb 26;4(1). [doi: 10.1186/s40900-018-0092-4]

16. Sandelowski M, Barroso J. Classifying the findings in qualitative studies. Qual Health Res 2003 Sep;13(7):905-923. [doi: 10.1177/1049732303253488] [Medline: 14502957]

17. Bazeley P. Analysing qualitative data: More than 'identifying themes'. Malays J Qual Res. 2009. URL: https://www. researchgate.net/publication/237458922 Analysing qualitative data More than 'identifying themes' [accessed 2021-01-14]

18. Braun V, Clarke V, Hayfield N. Thematic Analysis. Handbook of Research Methods in Health Social Sciences. Singapore: Springer; 2019. URL: https://www.springer.com/gp/book/9789811052507 [accessed 2020-06-15]

19. Ziebland S, Coulter A, Calabrese J, Locock L. Understanding and Using Health Experiences: Improving patient care. UK: Oxford University Press; 2013.

20. O'Brien M, Clark D. Use of unsolicited first-person written illness narratives in research: systematic review. J Adv Nurs 2010 Aug;66(8):1671-1682. [doi: 10.1111/j.1365-2648.2010.05349.x] [Medline: 20557382]

21. Banerjee AK, Okun S, Edwards IR, Wicks P, Smith MY, Mayall SJ, Patient-Reported Outcomes Safety Event Reporting (PROSPER) Consortium. Patient-Reported Outcome Measures in Safety Event Reporting: PROSPER Consortium guidance. Drug Saf 2013 Dec;36(12):1129-1149 [FRE Full text] [doi: 10.1007/s40264-013-0113-z] [Medline: 24092596]

22. Cella DF, Lloyd SR. Data collection strategies for patient-reported information. Quality Management in Health Care 1994;2(4):28-35. [doi: 10.1097/00019514-199422000-00006]

23. Howell D, Fitch M, Bakker D, Green E, Sussman J, Mayo S, et al. Core domains for a person-focused outcome measurement system in cancer (PROMS-Cancer Core) for routine care: a scoping review and Canadian Delphi Consensus. Value Health 2013;16(1):76-87 [FREE Full text] [doi: 10.1016/j.jval.2012.10.017] [Medline: 23337218]

24. Gale NK, Heath G, Cameron E, Rashid S, Redwood S. Using the framework method for the analysis of qualitative data in multi-disciplinary health research. BMC Med Res Methodol 2013 Sep 18;13:117 [FREE Full text] [doi: 10.1186/1471-2288-13-117] [Medline: 24047204]

25. Smith J, Firth J. Qualitative data analysis: the framework approach. Nurse Res 2011;18(2):52-62. [doi: 10.7748/nr2011.01.18.2.52.c8284] [Medline: 21319484]

26. Boyce S, Nassar N, Lee CYY, Suen MK, Al Zahrani S, Gladman MA. Young-onset colorectal cancer in New South Wales: a population-based study. Med J Aust 2016 Nov 21;205(10):465-470. [doi: 10.5694/mja16.00237] [Medline: 27852185]

27. Feletto E, Yu X, Lew J, St John D, Jenkins M, Macrae F, et al. Trends in Colon and Rectal Cancer Incidence in Australia from 1982 to 2014: Analysis of Data on Over 375,000 Cases. Cancer Epidemiol Biomarkers Prev 2018 Dec 07;28(1):83-90. [doi: 10.1158/1055-9965.epi-18-0523]

28. Ahnen DJ, Wade SW, Jones WF, Sifri R, Mendoza Silveiras J, Greenamyer J, et al. The Increasing Incidence of Young-Onset Colorectal Cancer: A Call to Action. Mayo Clinic Proceedings 2014 Feb;89(2):216-224 [FREE Full text] [doi: 10.1016/j.mayocp.2013.09.006]

29. Connell LC, Mota JM, Braghiroli MI, Hoff PM. The Rising Incidence of Younger Patients With Colorectal Cancer: Questions About Screening, Biology, and Treatment. Curr Treat Options Oncol 2017 Apr;18(4):23. [doi: 10.1007/s11864-017-0463-3] [Medline: 28391421]

30. Taggarshe D, Rehil N, Sharma S, Flynn JC, Damadi A. Colorectal cancer: are the "young" being overlooked? Am J Surg 2013 Mar;205(3):312-6; discussion 316. [doi: 10.1016/j.amjsurg.2012.10.016] [Medline: 23414955]

31. Yeo HB, Betel D, Abelson JS, Zheng XE, Yantiss R, Shah MA. Early-onset Colorectal Cancer is Distinct From Traditional Colorectal Cancer. Clin Colorectal Cancer 2017 Dec;16(4):293-299.e6. [doi: 10.1016/j.clcc.2017.06.002] [Medline: 29033218]

32. Abdelsattar ZM, Wong SL, Regenbogen SE, Jomaa DM, Hardiman KM, Hendren S. Colorectal cancer outcomes and treatment patterns in patients too young for average-risk screening. Cancer 2016 Mar 15;122(6):929-934 [FREE Full text] [doi: 10.1002/cncr.29716] [Medline: 26808454]

33. Araghi M, Soerjomataram I, Bardot A, Ferlay J, Cabasag CJ, Morrison DS, et al. Changes in colorectal cancer incidence in seven high-income countries: a population-based study. The Lancet Gastroenterology \& Hepatology 2019 Jul;4(7):511-518. [doi: 10.1016/s2468-1253(19)30147-5]

34. Macrae F. Colorectal cancer: epidemiology, risk factors, protective factors. URL: https://www.uptodate.com/contents/ colorectal-cancer-epidemiology-risk-factors-and-protective-factors [accessed 2020-10-15]

35. Siegel RL, Torre LA, Soerjomataram I, Hayes RB, Bray F, Weber TK, et al. Global patterns and trends in colorectal cancer incidence in young adults. Gut 2019 Dec;68(12):2179-2185. [doi: 10.1136/gutjnl-2019-319511] [Medline: 31488504] 
36. Siminoff LA, Rogers HL, Thomson MD, Dumenci L, Harris-Haywood S. Doctor, what's wrong with me? Factors that delay the diagnosis of colorectal cancer. Patient Educ Couns 2011 Sep;84(3):352-358 [FREE Full text] [doi: 10.1016/j.pec.2011.05.002] [Medline: 21621950]

37. Arndt V, Merx H, Stegmaier C, Ziegler H, Brenner H. Quality of Life in Patients With Colorectal Cancer 1 Year After Diagnosis Compared With the General Population: A Population-Based Study. JCO 2004 Dec 01;22(23):4829-4836. [doi: 10.1200/jco.2004.02.018]

38. Arndt V, Merx H, Stegmaier C, Ziegler H, Brenner H. Restrictions in quality of life in colorectal cancer patients over three years after diagnosis: a population based study. Eur J Cancer 2006 Aug;42(12):1848-1857. [doi: 10.1016/j.ejca.2006.01.059] [Medline: 16829069]

39. Gordon LG, Lynch BM, Beesley VL, Graves N, McGrath C, O'Rourke P, et al. The Working After Cancer Study (WACS): a population-based study of middle-aged workers diagnosed with colorectal cancer and their return to work experiences. BMC Public Health 2011 Jul 29;11:604 [FREE Full text] [doi: 10.1186/1471-2458-11-604] [Medline: 21798072]

40. Lamprell K, Braithwaite J. When Patients Tell Their Own Stories: A Meta-Narrative Study of Web-Based Personalized Texts of 214 Melanoma Patients' Journeys in Four Countries. Qual Health Res 2018 Aug;28(10):1564-1583. [doi: 10.1177/1049732317742623] [Medline: 29173015]

41. Cognetta-Rieke C, Guney S. Analytical Insights from Patient Narratives: The Next Step for Better Patient Experience. J Patient Exp 2014 May;1(1):20-22 [FREE Full text] [doi: 10.1177/237437431400100105] [Medline: 28725797]

42. Lamprell K, Rapport F, Braithwaite J. Narrativizing cancer patients' longitudinal experiences of care: qualitative inquiry into lived and online melanoma stories. In: Transforming Health Care With Qualitative Research. UK: Routledge; Oct 10, 2020:2020.

43. Fielding N, Lee R, Blank G. The SAGE Handbook of Online Research Methods. UK: SAGE Publications; 2016.

44. Pellino G, Simillis C, Qiu S, Rasheed S, Mills S, Warren O, et al. Social media and colorectal cancer: A systematic review of available resources. PLoS One 2017;12(8):e0183031 [FREE Full text] [doi: 10.1371/journal.pone.0183031] [Medline: 28832603]

45. Beusterien K, Tsay S, Gholizadeh S, Su Y. Real-world experience with colorectal cancer chemotherapies: patient web forum analysis. Ecancermedicalscience 2013;7:361 [FREE Full text] [doi: 10.3332/ecancer.2013.361] [Medline: 24143155]

46. Drewniak D, Glässel A, Hodel M, Biller-Andorno N. Risks and Benefits of Web-Based Patient Narratives: Systematic Review. J Med Internet Res 2020 Mar 26;22(3):e15772. [doi: 10.2196/15772]

47. Burles MC, Bally JMG. Ethical, Practical, and Methodological Considerations for Unobtrusive Qualitative Research About Personal Narratives Shared on the Internet. International Journal of Qualitative Methods 2018 Jul 17;17(1):160940691878820. [doi: 10.1177/1609406918788203]

48. National Health and Medical Research Council. National Statement on Ethical Conduct in Human Research (2007). Canberra, Australia; 2018. URL: https://www.nhmrc.gov.au/about-us/publications/ national-statement-ethical-conduct-human-research-2007-updated-2018 [accessed 2020-06-05]

49. Orb A, Eisenhauer L, Wynaden D. Ethics in qualitative research. J Nurs Scholarsh 2001;33(1):93-96. [doi: 10.1111/j.1547-5069.2001.00093.x] [Medline: 11253591$]$

50. Aluwihare-Samaranayake D. Ethics in Qualitative Research: A View of the Participants' and Researchers' World from a Critical Standpoint. International Journal of Qualitative Methods 2012 Apr 01;11(2):64-81. [doi:

10.1177/160940691201100208]

51. QSR International. NVivo qualitative data analysis. URL: https://www.qsrinternational.com/ nvivo-qualitative-data-analysis-software/home [accessed 2020-11-06]

52. Charon R. Narrative Medicine: Attention, Representation, Affiliation. Narrative 2005;13(3):261-270 [FREE Full text] [doi: 10.1353/nar.2005.0017]

53. Besson A, Deftereos I, Chan S, Faragher IG, Kinsella R, Yeung JM. Understanding patient-reported outcome measures in colorectal cancer. Future Oncol 2019 Apr;15(10):1135-1146. [doi: 10.2217/fon-2018-0723] [Medline: 30880455]

54. Christalle E, Zeh S, Hahlweg P, Kriston L, Härter M, Scholl I. Assessment of patient centredness through patient-reported experience measures (ASPIRED): protocol of a mixed-methods study. BMJ Open 2018 Oct 21;8(10):e025896 [FREE Full text] [doi: 10.1136/bmjopen-2018-025896] [Medline: $\underline{\text { 30344183] }}$

55. Rutherford C, Müller F, Faiz N, King MT, White K. Patient-reported outcomes and experiences from the perspective of colorectal cancer survivors: meta-synthesis of qualitative studies. J Patient Rep Outcomes 2020 Apr 25;4(1):27 [FREE Full text] [doi: 10.1186/s41687-020-00195-9] [Medline: 32335745]

56. Brundage MD, Smith KC, Little EA, Bantug ET, Snyder CF, PRO Data Presentation Stakeholder Advisory Board. Communicating patient-reported outcome scores using graphic formats: results from a mixed-methods evaluation. Qual Life Res 2015 Oct;24(10):2457-2472 [FREE Full text] [doi: 10.1007/s11136-015-0974-y] [Medline: 26012839]

57. Pitt S. Qualitative methods and patient-reported outcome measures. 2017. URL: https://www.aasurg.org/wp-content/uploads/ 2017/10/Pitt-Qualitative-Methods-PROM.pdf [accessed 2020-10-15]

58. Hadi M, Gibbons E, Fitzpatrick R. A structured review of patient-reported outcome measures for colorectal cancer. 2010. URL: https://www.ndph.ox.ac.uk/files/research/colorectal-cancer-review-final-2010.pdf [accessed 2020-08-10] 
59. Wong CK, Chen J, Yu CL, Sham M, Lam CL. Systematic review recommends the European Organization for Research and Treatment of Cancer colorectal cancer-specific module for measuring quality of life in colorectal cancer patients. J Clin Epidemiol 2015 Mar;68(3):266-278. [doi: 10.1016/j.jclinepi.2014.09.021] [Medline: 25455838]

60. EuroQoL Research Foundation. EQ-5D-5L User Guide. 2019. URL: https://euroqol.org/eq-5d-instruments/eq-5d-51-about/ [accessed 2020-06-10]

61. Ganesh V, Agarwal A, Popovic M, Cella D, McDonald R, Vuong S, et al. Comparison of the FACT-C, EORTC QLQ-CR38, and QLQ-CR29 quality of life questionnaires for patients with colorectal cancer: a literature review. Support Care Cancer 2016 Aug;24(8):3661-3668. [doi: 10.1007/s00520-016-3270-7] [Medline: 27193118]

62. Ameri H, Yousefi M, Yaseri M, Nahvijou A, Arab M, Akbari Sari A. Mapping EORTC-QLQ-C30 and QLQ-CR29 onto EQ-5D-5L in Colorectal Cancer Patients. J Gastrointest Cancer 2020 Mar;51(1):196-203. [doi: 10.1007/s12029-019-00229-6] [Medline: 30977049]

63. Wagland R, Recio-Saucedo A, Simon M, Bracher M, Hunt K, Foster C, et al. Development and testing of a text-mining approach to analyse patients' comments on their experiences of colorectal cancer care. BMJ Qual Saf 2016 Aug;25(8):604-614. [doi: 10.1136/bmjqs-2015-004063] [Medline: 26512131]

64. Benson T, Potts HW. A short generic patient experience questionnaire: howRwe development and validation. BMC Health Serv Res 2014 Oct 22;14:499 [FREE Full text] [doi: 10.1186/s12913-014-0499-z] [Medline: 25331177]

65. Doyle C, Lennox L, Bell D. A systematic review of evidence on the links between patient experience and clinical safety and effectiveness. BMJ Open 2013 Jan 03;3(1) [FREE Full text] [doi: 10.1136/bmjopen-2012-001570] [Medline: 23293244]

66. Robert G, Cornwall J, Brearley S. What matters to patients? Developing the evidence base for measuring and improving the patient experience. NHS Institute for Innovation \& Improvement. URL: http://www.wales.nhs.uk/sites3/documents/ 420/Final\%20Project\%20Report\%20pdf\%20doc\%20january\%202012\%20(2).pdf [accessed 2020-08-10]

67. Kingsley C, Patel S. Patient-reported outcome measures and patient-reported experience measures. BJA Education 2017 Apr;17(4):137-144. [doi: 10.1093/bjaed/mkw060]

68. Lyratzopoulos G, Saunders CL, Abel GA, McPhail S, Neal RD, Wardle J, et al. The relative length of the patient and the primary care interval in patients with 28 common and rarer cancers. Br J Cancer 2015 Mar 31;112 Suppl 1:S35-S40 [FREE Full text] [doi: 10.1038/bjc.2015.40] [Medline: 25734380]

69. National Collaborating Centre for Cancer. Colorectal Cancer: The Diagnosis and Management of Colorectal Cancer. National Institute for Health and Clinical Excellence: Guidance 2011. [Medline: 23346607]

70. Kim J. Understanding Narrative Inquiry: The Crafting and Analysis of Stories as Research. Texas Tech University, USA: Sage Publications; 2016:185-224.

71. Tran Y, Lamprell K, Nic Giolla Easpaig B, Arnolda G, Braithwaite J. What information do patients want across their cancer journeys? A network analysis of cancer patients' information needs. Cancer Med 2019 Jan;8(1):155-164 [FREE Full text] [doi: 10.1002/cam4.1915] [Medline: 30525298]

72. Saposnik G, Redelmeier D, Ruff CC, Tobler PN. Cognitive biases associated with medical decisions: a systematic review. BMC Med Inform Decis Mak 2016 Nov 03;16(1):138 [FREE Full text] [doi: 10.1186/s12911-016-0377-1] [Medline: 27809908]

73. Croskerry P. From Mindless to Mindful Practice — Cognitive Bias and Clinical Decision Making. N Engl J Med 2013 Jun 27;368(26):2445-2448. [doi: 10.1056/nejmp1303712]

74. Dodd N, Carey M, Mansfield E. Knowledge of colorectal cancer risk factors and screening recommendations: a cross-sectional study of regional Australian general practice patients. Public Health Res Pract. 2017. URL: https://www.phrp.com.au/issues/ december-2017-volume-27-issue-5/knowledge-of-colorectal-cancer-risk-factors-and-screening-recommendationsa-cross-sectional-study-of-regional-australian-general-practice-patients/ [accessed 2020-01-01]

75. Campos FG. Colorectal cancer in young adults: A difficult challenge. World J Gastroenterol 2017 Jul 28;23(28):5041-5044 [FREE Full text] [doi: 10.3748/wjg.v23.i28.5041] [Medline: 28811701]

76. Underhill M, Germansky K, Yurgelun M. Advances in Hereditary Colorectal and Pancreatic Cancers. Clin Ther 2016 Jul;38(7):1600-1621 [FREE Full text] [doi: 10.1016/j.clinthera.2016.03.017] [Medline: 27045993]

\section{Abbreviations}

EORTC-QLQ-CR29: European Organization for Research and Treatment of Cancer-Quality of Life Questionnaire-29-item colon and rectum cancer-site specific

EQ-5D: European Quality of Life Questionnaire-5 dimension

FACT-C: Functional Assessment of Cancer Therapy-Colorectal

PRE: patient-reported experience

PRO: patient-reported outcome

PROD: personal recollections organized as data

SDI-21: Social Difficulties Inventory instrument-21 item 
Edited by G Eysenbach; submitted 15.10.20; peer-reviewed by N Schaeffeler, Z Zrubka; comments to author 31.12.20; revised version received 12.01.21; accepted 21.01.21; published 26.02.21

Please cite as:

Lamprell K, Fajardo Pulido D, Tran Y, Nic Giolla Easpaig B, Liauw W, Arnolda G, Braithwaite J

Personal Accounts of Young-Onset Colorectal Cancer Organized as Patient-Reported Data: Protocol for a Mixed Methods Study JMIR Res Protoc 2021;10(2):e25056

URL: https://www. researchprotocols.org/2021/2/e25056

doi: $\underline{10.2196 / 25056}$

PMID: 33635274

CKlay Lamprell, Diana Fajardo Pulido, Yvonne Tran, Bróna Nic Giolla Easpaig, Winston Liauw, Gaston Arnolda, Jeffrey Braithwaite. Originally published in JMIR Research Protocols (http://www.researchprotocols.org), 26.02.2021. This is an open-access article distributed under the terms of the Creative Commons Attribution License (https://creativecommons.org/licenses/by/4.0/), which permits unrestricted use, distribution, and reproduction in any medium, provided the original work, first published in JMIR Research Protocols, is properly cited. The complete bibliographic information, a link to the original publication on http://www.researchprotocols.org, as well as this copyright and license information must be included. 